\title{
Subgroup identification of early preterm birth (ePTB): informing a future prospective enrichment clinical trial design
}

\author{
Chuanwu Zhang ${ }^{1 *}$ (D) Lili Garrard², John Keighley', Susan Carlson ${ }^{3}$ and Byron Gajewski ${ }^{1}$
}

\begin{abstract}
Background: Despite the widely recognized association between the severity of early preterm birth (ePTB) and its related severe diseases, little is known about the potential risk factors of ePTB and the sub-population with high risk of ePTB. Moreover, motivated by a future confirmatory clinical trial to identify whether supplementing pregnant women with docosahexaenoic acid (DHA) has a different effect on the risk subgroup population or not in terms of ePTB prevalence, this study aims to identify potential risk subgroups and risk factors for ePTB, defined as babies born less than 34 weeks of gestation.

Methods: The analysis data ( $N=3,994,872)$ were obtained from CDC and NCHS' 2014 Natality public data file. The sample was split into independent training and validation cohorts for model generation and model assessment, respectively. Logistic regression and CART models were used to examine potential ePTB risk predictors and their interactions, including mothers' age, nativity, race, Hispanic origin, marital status, education, pre-pregnancy smoking status, pre-pregnancy BMI, pre-pregnancy diabetes status, pre-pregnancy hypertension status, previous preterm birth status, infertility treatment usage status, fertility enhancing drug usage status, and delivery payment source.
\end{abstract}

Results: Both logistic regression models with either 14 or 10 ePTB risk factors produced the same C-index (0.646) based on the training cohort. The C-index of the logistic regression model based on 10 predictors was 0.645 for the validation cohort. Both C-indexes indicated a good discrimination and acceptable model fit. The CART model identified preterm birth history and race as the most important risk factors, and revealed that the subgroup with a preterm birth history and a race designation as Black had the highest risk for ePTB. The c-index and misclassification rate were 0.579 and 0.034 for the training cohort, and 0.578 and 0.034 for the validation cohort, respectively.

Conclusions: This study revealed 14 maternal characteristic variables that reliably identified risk for ePTB through either logistic regression model and/or a CART model. Moreover, both models efficiently identify risk subgroups for further enrichment clinical trial design.

Keywords: Early preterm birth, Risk factor, Interaction, Classification and regression tree, Logistic regression, Enrichment trial design

\footnotetext{
* Correspondence: czhang4@kumc.edu

${ }^{1}$ Department of Biostatistics, University of Kansas Medical Center, Mail Stop

1026, 3901 Rainbow Blvd., Kansas City, KS 66160, USA

Full list of author information is available at the end of the article
} 


\section{Background}

Preterm birth, also known as premature birth, is the birth of a baby at less than 37 weeks of gestational age (http:// www.who.int/mediacentre/factsheets/fs363/en/, http://www. cdc.gov/reproductivehealth/maternalinfanthealth/preterm birth.htm). Preterm birth occurs in $9.57 \%$ of all U.S. births each year [1]. Worldwide, approximately 15 million babies are born prematurely each year (http://www. who.int/mediacentre/factsheets/fs363/en/). Preterm birth increases the risk of many severe health outcomes. Infants born preterm are more likely to experience early death than are infants born at term [2, 3]; and preterm birth is the leading cause of both neonatal death and long-term neurological disabilities for children in the United States (http://www.cdc.gov/reproductivehealth/ maternalinfanthealth/pretermbirth.htm) [4]. Moreover, adults who were born preterm are at increased risk of having hypertension $[5,6]$, mental health disorders, chronic respiratory disease, and neurologic and learning disabilities [7]. Preterm birth causes great social and medical burdens both in the U.S. [8,9] and worldwide [10-12]. Early preterm birth (ePTB)-birth at less than 34 weeks - has the highest risk of mortality and other diseases in adulthood $[13,14]$. The importance of prevention is evident for preterm birth, including ePTB. Consequently, to identify the risk factors of preterm birth, especially for $\mathrm{ePTB}$, is a highly important step that will provide valuable information for subsequent enrichment clinical trial designs of targeted preventions and/or treatment.

Several recent studies have explored the risk factors for ePTB [15-18]. Researchers have identified a few potential maternal risk factors associated with preterm birth including maternal hypertension [5], Factor V Leiden [19], lower genital tract inflammatory milieu [20], prior preeclampsia [18], and Crohn's disease [21]. Not only were these trials limited in statistical power, few studies explored potential risk factors for ePTB, which has a higher risk for poor health outcomes [13, 22]. In addition, interaction among the risk factors was typically not considered, despite the important role played by the interaction among risk factors in the prevention and treatment of preterm birth, including ePTB. From a practical perspective, this analysis is motivated by a desire to inform a future confirmatory clinical trial designed to identify whether supplementing pregnant women with docosahexaenoic acid (DHA) can differently reduce the rate of $\mathrm{ePTB}$ for the subgroups. DHA supplementation provides a high yield, low risk provocative strategy to reduce ePTB delivery in the U.S. by up to 75\% [23]. However, little is known regarding the effect profile of DHA on various populations; and it is possible for DHA to have different effects on different risk subgroups.

Based on findings from previous studies on preterm birth and our future research interest, the specific aim for this study is to identify potential risk subgroups and risk factors for the main outcome, ePTB, defined previously as babies born prior to 34 weeks of gestation $[14,24]$. We applied and compared both logistic regression and classification and regression tree (CART) models to identify potential risk subgroups and risk factors from maternal demographic characteristics $[4,25]$ and maternal pre-pregnancy characteristics for ePTB. To the author's best knowledge, this is the first study to explore the association of ePTB with risk factors, the interactions among the risk factors, and to identify potential subgroups to inform future enrichment trial designs.

\section{Methods}

\section{4 natality public data file}

The ePTB population data used for these analyses were obtained from the National Vital Statistics System's 2014 Natality public data file, compiled by the Centers for Disease Control and Prevention's (CDC) National Center for Health Statistics (NCHS). Since federal law mandates national collection and publication of births and other vital statistical data, all births occurring and registered within the U.S. in 2014 were collected directly from the 50 U.S. states, New York City, and the District of Columbia (DC) [26]. The overall database contains $3,998,175$ records comprised of demographic characteristics of the mother, father, and the child (e.g., gestation), maternal prenatal care, pregnancy history, and health data, etc. The public data and the corresponding user's guide are available from the website: http://www.cdc.gov/nchs/ data_access/Vitalstatsonline.htm

\section{Study population}

After excluding 3303 cases for which the gestation period from the original 2014 Natality public data file was unknown, the final analysis file for the current study included 3,994,872 records. Since the main outcome variable is $\mathrm{ePTB}$, a binary flag variable representing the ePTB status (i.e., $1=<34$ weeks: ePTB and $0=\geq 34$ weeks) was created in the analysis file. The analysis file included selected maternal demographic characteristics considered relevant to ePTB, such as mothers' age, mothers' nativity, mothers' race, mothers' Hispanic origin, marital status, mothers' education, delivery payment source. Delivery payment source was included as an additional covariate that may provide additional information on the implications of socioeconomic status for ePTB. Maternal pre-pregnancy characteristics and medical history were also included in the ePTB risk factor analysis. These factors included smoking status, body mass index (BMI), diabetes status, hypertension status, previous preterm birth status, infertility treatment usage status and fertility enhancing drug usage status. In total, 14 maternal variables from the database were used as 
risk predictors in statistical models. The father's demographic characteristics were not considered for this study.

A total of 142,851 (3.58\%) observations from the analysis file contained at least one missing value for some of the predictors and those predictors were categorized as "missing." Predictors with responses of "Unknown," "Not Stated," "Not Applicable," and "Other," were categorized together as shown in the descriptive statistics listed in Tables 1 and 2.

\section{Statistical analysis \\ Training and validation datasets}

The large sample size allowed for independent training and validation cohorts. The overall sample was divided randomly into a training cohort (70\%) and a validation cohort (30\%), stratifying by ePTB status to ensure a balanced partition. Descriptive statistics were summarized to compare the demographic and pre-pregnancy information between the two cohorts of data. The training sample was used to build models via both logistic regression and CART and the validation sample was used to evaluate the models obtained from the training cohort.

\section{Logistic regression}

In order to investigate the association of ePTB with the potential risk factors, a multivariate logistic regression model was applied to estimate odds ratios (OR) and the corresponding 95\% confidence intervals (CI). All predictors entered the model and they were selected via backward elimination. We set the significance level to stay in the model for a predictor to 0.05 . A further simplified logistic regression model was fitted using 10 covariates to explore risk subgroups of ePTB. The predicted probabilities were calculated for the validation cohort based on the simplified model obtained from the training cohort. Based on the validation cohort, the calibration plot was generated to compare the average predicted probabilities and the average observed probabilities. The c-index was calculated to identify the model discriminatory capacity in terms of the training and validation cohorts.

\section{CART model}

CART model can be a very useful complement to a logistic regression model because the CART model can identify unknown interactions among the risk factors of ePTB. CART is a nonparametric method that derives hidden patterns in data by constructing a series of binary splits on the outcome of interest [27-29]. The most discriminating predictor is selected to form the first partition based on the ability of the variables to minimize the within-group variance of the dependent variable, so the observations within each subgroup share the same characteristics that influence the probability of belonging to the interested response group [30]. This step is executed repeatedly to each partition until the sample size of each subgroup (i.e., a terminal node) is at or below a prespecified level. In this study, the terminal node was specified as $0.5 \%$ of the total sample (either the training sample or the validation sample). A maximum tree first was constructed and standard pruning strategies were then applied to arrive at a parsimonious tree with a low misclassification rate and a high discriminatory capacity [31]. The final CART model can be visualized as an upside-down tree with the parent node of the tree containing the entire sample. Additional child nodes can be created using the Gini splitting rule for binary outcomes [32], and the terminal nodes are where predictions and inferences are made. The training cohort was used to generate an appropriate CART tree, and the validation cohort was utilized to evaluate the CART tree via the Cindex and the misclassification rate.

All statistical tests were two-tailed with $p \leq 0.05$ as the statistically significant level. The CART analysis was executed in SAS Enterprise Miner Workstation 13.1 [32], and all other statistical analyses and the data management were conducted with SAS 9.4.

\section{Results}

Characteristics of the study population and training and validation datasets

As previously mentioned, the analysis file included $3,994,872$ records which contained 134,009 cases of ePTB $(<34$ weeks) and 3,860,863 cases of baby birth $\geq$ 34 weeks of gestation. The characteristics of the subjects stratified by ePTB status are shown in Table 1 . For the training and validation cohorts, $70 \%(N=2,796,411)$ and $30 \%(N=1,198,461)$ of the total sample were generated for each cohort, respectively. The frequencies and related percentages of each predictor were similar after the random split stratified by the ePTB status, indicating that the partition is well-balanced (Table 2).

\section{Logistic regression \\ 14-predictor model}

Table 3 showed results from the logistic regression analysis for prevalence of ePTB with all 14 predictor variables. A relatively higher ePTB prevalence was observed in the older mother populations compared to younger mothers in the $\leq 24$ years old reference group. The adjusted OR $(95 \%$ CI $)$ were $1.013(0.995,1.032), 1.130$ $(1.108,1.152)$, and $1.354(1.325,1.385)$ for mothers in the age groups of 25-29 years (non-significant, $p=0.169$ ), 3034 years, and $\geq 35$ years, respectively. Mothers born outside of the U.S. were less likely to experience ePTB compared to mothers born in the U.S. with an adjusted OR $(95 \% \mathrm{CI})$ of $0.880(0.863,0.898)$. Black mothers and American Indian/Alaskan Native/Asian or Pacific Islander 
Table 1 Subject demography information

\begin{tabular}{|c|c|c|}
\hline \multirow[t]{3}{*}{ Variable } & \multicolumn{2}{|c|}{ Newborn Gestational Age } \\
\hline & $<34$ weeks: ePTB & $\geq 34$ weeks \\
\hline & $N=134009$ & $N=3860863$ \\
\hline \multicolumn{3}{|l|}{ Mothers' Age (\%) } \\
\hline$\leq 24$ Years & $40711(30.38)$ & $1094793(28.36)$ \\
\hline 25-29 Years & $34831(25.99)$ & $1112643(28.82)$ \\
\hline 30-34 Years & $33578(25.06)$ & $1049775(27.19)$ \\
\hline$\geq 35$ Years & $24889(18.57)$ & $603652(15.64)$ \\
\hline \multicolumn{3}{|l|}{ Mothers' Nativity (\%) } \\
\hline Born in U.S. & $107578(80.28)$ & $2996531(77.61)$ \\
\hline Born Outside U.S. /Unknown/Not Stated & $26431(19.72)$ & $864332(22.39)$ \\
\hline \multicolumn{3}{|l|}{ Mothers' Race (\%) } \\
\hline White & $88185(65.81)$ & $2938466(76.11)$ \\
\hline Black & $36554(27.28)$ & $603921(15.64)$ \\
\hline American Indian/Alaskan Native/Asian or Pacific Islander & $9270(6.92)$ & $318476(8.25)$ \\
\hline \multicolumn{3}{|l|}{ Mothers' Hispanic Origin (\%) } \\
\hline Non-Hispanic/Hispanic Origin Not Stated & $105011(78.36)$ & $2968422(76.88)$ \\
\hline Hispanic & $28998(21.64)$ & $892441(23.12)$ \\
\hline \multicolumn{3}{|l|}{ Marital Status (\%) } \\
\hline Married & $65594(48.95)$ & $2323620(60.18)$ \\
\hline Unmarried & $68415(51.05)$ & $1537243(39.82)$ \\
\hline \multicolumn{3}{|l|}{ Mothers' Education (\%) } \\
\hline$\leq$ High School or GED/Unknown & $62819(46.88)$ & $1512489(39.17)$ \\
\hline Associate/Some College Credit & $37338(27.86)$ & $1086153(28.13)$ \\
\hline$\geq$ Bachelor's & $29145(21.75)$ & $1124077(29.11)$ \\
\hline Missing & $4707(3.51)$ & $138144(3.58)$ \\
\hline \multicolumn{3}{|l|}{ Pre-pregnancy Smoking Status (\%) } \\
\hline Nonsmoker & $108663(81.09)$ & $3258557(84.40)$ \\
\hline Smoker/Unknown/Not Stated & $20639(15.40)$ & $464162(12.02)$ \\
\hline Missing & $4707(3.51)$ & $138144(3.58)$ \\
\hline \multicolumn{3}{|l|}{ Pre-pregnancy BMI (\%) } \\
\hline Under Weight-Normal $\leq 24.9$ & $55824(41.66)$ & $1785913(46.26)$ \\
\hline Overweight 25.0-29.9 & $30288(22.60)$ & $918380(23.79)$ \\
\hline Obesity $\geq 30.0 /$ Unknown/Not Stated & $43190(32.23)$ & $1018426(26.38)$ \\
\hline Missing & $4707(3.51)$ & $138144(3.58)$ \\
\hline \multicolumn{3}{|l|}{ Pre-pregnancy Diabetes Status (\%) } \\
\hline No/Unknown/Not Stated & $126901(94.70)$ & $3694967(95.70)$ \\
\hline Yes & $2401(1.79)$ & $27752(0.72)$ \\
\hline Missing & $4707(3.51)$ & $138144(3.58)$ \\
\hline \multicolumn{3}{|l|}{ Pre-pregnancy Hypertension Status (\%) } \\
\hline No/Unknown/Not Stated & $123932(92.48)$ & $3667289(94.99)$ \\
\hline Yes & $5370(4.01)$ & $55430(1.44)$ \\
\hline Missing & $4707(3.51)$ & $138144(3.58)$ \\
\hline \multicolumn{3}{|l|}{ Previous Preterm Birth Status (\%) } \\
\hline No/Unknown/Not Stated & $118468(88.40)$ & 3626879 (93.94) \\
\hline
\end{tabular}


Table 1 Subject demography information (Continued)

\begin{tabular}{|c|c|c|}
\hline Yes & $10834(8.08)$ & $95840(2.48)$ \\
\hline Missing & $4707(3.51)$ & $138144(3.58)$ \\
\hline \multicolumn{3}{|l|}{ Infertility Treatment Usage Status (\%) } \\
\hline No/Unknown/Not Stated & 122859 (91.68) & $3669850(95.05)$ \\
\hline Yes & $6443(4.81)$ & $52869(1.37)$ \\
\hline Missing & $4707(3.51)$ & $138144(3.58)$ \\
\hline \multicolumn{3}{|l|}{ Fertility Enhancing Drug Usage Status (\%) } \\
\hline No/Not Applicable/Unknown/Not Stated & $126582(94.46)$ & $3697856(95.78)$ \\
\hline Yes & $2720(2.03)$ & $24863(0.64)$ \\
\hline Missing & $4707(3.51)$ & $138144(3.58)$ \\
\hline \multicolumn{3}{|l|}{ Delivery Payment Source (\%) } \\
\hline Medicaid & $65048(48.54)$ & $1598851(41.41)$ \\
\hline Private Insurance & $51753(38.62)$ & $1771814(45.89)$ \\
\hline Self-pay/Other/Unknown & $12501(9.33)$ & 352054 (9.12) \\
\hline Missing & $4707(3.51)$ & $138144(3.58)$ \\
\hline
\end{tabular}

mothers were more likely to have an ePTB compared to White mothers with adjusted OR (95\% CI) of 1.773 $(1.743,1.803)$ and $1.096(1.066,1.127)$, respectively. Mothers of Hispanic origin had a slightly higher ePTB prevalence compared to mothers of non-Hispanic origin with an adjusted OR (95\% CI) of 1.033 (1.013, 1.053). ePTB was more likely to occur in the unmarried mother population compared to married mothers with an adjusted OR (95\% CI) of 1.326 (1.304, 1.347).

Mothers with an associate degree or some college credit and mothers with a bachelor's degree or higher education were less likely to experience ePTB compared to mothers with a high school/general educational development (GED) or less education. The corresponding adjusted OR (95\% CI) for each subgroup was 0.842 (0.828, $0.856)$ and $0.713(0.698,0.729)$, respectively. Results from the subgroup with missing mother's education were non-significant $(p=0.873)$. In addition, since all the observations with missing predictors were all from the same subset, for the following parameters after mothers' education, missing observations were automatically excluded from the analysis, and the corresponding parameters were automatically set to 0 due to they are from the same subset.

Some maternal pre-pregnancy characteristics and medical history factors were also found to be related to ePTB. For Pre-pregnancy BMI, mothers in the overweight subgroup had a slightly lower prevalence of ePTB $(p=0.047)$, with an adjusted OR (95\% CI) of 0.983 $(0.966,1.000)$ compared to mothers with underweight and/or normal BMI. However, the opposite result was obtained for the obese subgroup with an adjusted OR (95\% CI) of $1.127(1.109,1.145)$, compared with the underweight and/or normal BMI mothers. For other pre-pregnancy risk factors (i.e., smoking status, diabetes status, hypertension status, and previous preterm birth status), mothers in each risk sub-category were more likely to have a higher prevalence of ePTB compared to mothers who did not have the abovementioned risk factors. The corresponding adjusted OR (95\% CI) were 1.183 (1.160, 1.206), 1.776 (1.685, 1.871), 1.984 (1.913, 2.056), 3.004 (2.929, 3.081), respectively.

In addition, mothers who used infertility treatment were much more likely to experience ePTB than those who had not used the infertility treatment, with an adjusted OR (95\% CI) of $5.103(4.888,5.328)$. On the other hand, a different outcome was observed with the usage of fertility enhancing drug. Mothers who used fertility enhancing drugs were less likely to have an ePTB compared to women who did not, with an adjusted OR (95\% CI) of $0.820(0.769,0.873)$. Compared to women whose payer was Medicaid, the adjusted OR (95\% CI) were $0.965(0.948,0.983)$ and $1.079(1.054,1.105)$ for women who had private insurance and self-pay, respectively. Mothers with private insurance had a slightly lower prevalence of ePTB; whereas mothers with self-paid delivery had a slightly higher prevalence of ePTB. Although the $p$-values for both comparisons were statistically significant $(<0.0001)$, the numerical differences were small.

\section{0-predictor model}

After examining results from the 14-predictor model, four covariates - mothers' nativity, mothers' Hispanic origin, fertility enhancing drug usage status, and delivery payment source - were excluded for having minimal effects on ePTB and to explore further a smaller set of potential risk subgroups for ePTB. Moreover, the same C-index (0.646) was obtained from both logistic regression 
Table 2 Univariate difference between training sample and validation sample

\begin{tabular}{|c|c|c|c|c|c|}
\hline \multirow[t]{3}{*}{ Variables } & \multicolumn{2}{|l|}{ Cohort } & \multirow{2}{*}{$\begin{array}{l}\text { Yes } \\
\text { Missing }\end{array}$} & \multirow{2}{*}{$\begin{array}{l}42787(1.53) \\
100214(3.58)\end{array}$} & \multirow{2}{*}{$\begin{array}{l}18013(1.50) \\
42637(3.56)\end{array}$} \\
\hline & Training & Validation & & & \\
\hline & $N=2796411$ & $N=1198461$ & \multicolumn{3}{|l|}{ Previous Preterm Birth Status (\%) } \\
\hline \multicolumn{3}{|l|}{ Mothers' Age (\%) } & No/Unknown/Not Stated & $2621496(93.75)$ & $1123851(93.77)$ \\
\hline$\leq 24$ Years & $794486(28.41)$ & $341018(28.45)$ & Yes & $74701(2.67)$ & $31973(2.67)$ \\
\hline 25-29 Years & 803113 (28.72) & 344361 (28.73) & Missing & $100214(3.58)$ & $42637(3.56)$ \\
\hline 30-34 Years & $758087(27.11)$ & $325266(27.14)$ & \multicolumn{3}{|l|}{ Infertility Treatment Usage Status (\%) } \\
\hline$\geq 35$ Years & $440725(15.76)$ & $187816(15.67)$ & No/Unknown/Not Stated & $2654757(94.93)$ & $1137952(94.95)$ \\
\hline \multicolumn{3}{|l|}{ Mothers' Nativity (\%) } & Yes & $41440(1.48)$ & $17872(1.49)$ \\
\hline Born in U.S. & $2172903(77.70)$ & $931206(77.70)$ & Missing & $100214(3.58)$ & $42637(3.56)$ \\
\hline $\begin{array}{l}\text { Born Outside U.S. /Unknown/ } \\
\text { Not Stated }\end{array}$ & $623508(22.30)$ & $267255(22.30)$ & \multicolumn{3}{|c|}{ Fertility Enhancing Drug Usage Status (\%) } \\
\hline \multicolumn{3}{|l|}{ Mothers' Race (\%) } & $\begin{array}{l}\text { No/Not Applicable/Unknown/ } \\
\text { Not Stated }\end{array}$ & 2676910 (95.73) & $1147528(95.75)$ \\
\hline White & \multirow{3}{*}{$\begin{array}{l}447972(16.02) \\
229324(8.20)\end{array}$} & $907536(75.73)$ & 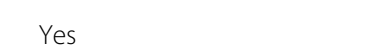 & $19287(0.69)$ & $8296(0.69)$ \\
\hline Black & & $192503(16.06)$ & Missing & $100214(3.58)$ & $42637(3.56)$ \\
\hline $\begin{array}{l}\text { American Indian/Alaskan } \\
\text { Native/Asian or Pacific Islander }\end{array}$ & & $98422(8.21)$ & Delivery Payment Source (\%) & & \\
\hline \multicolumn{3}{|l|}{ Mothers' Hispanic Origin (\%) } & Medicaid & 1164617 (41.65) & $499282(41.66)$ \\
\hline \multirow{2}{*}{$\begin{array}{l}\text { Non-Hispanic/Hispanic Origin } \\
\text { Not Stated }\end{array}$} & \multirow[t]{2}{*}{$2151766(76.95)$} & \multirow[t]{2}{*}{$921667(76.90)$} & Private Insurance & $1276362(45.64)$ & $547205(45.66)$ \\
\hline & & & Self-pay/Other/Unknown & $255218(9.13)$ & 109337 (9.12) \\
\hline Hispanic & $644645(23.05)$ & $276794(23.10)$ & Missing & $100214(3.58)$ & $42637(3.56)$ \\
\hline \multicolumn{3}{|l|}{ Marital Status (\%) } & \multicolumn{3}{|l|}{ Newborn Gestational Age (\%) } \\
\hline Married & $1672583(59.81)$ & $716631(59.80)$ & < 34 weeks: ePTB & $93751(3.35)$ & $40258(3.36)$ \\
\hline Unmarried & $1123828(40.19)$ & $481830(40.20)$ & $\geq 34$ weeks & $2702660(96.65)$ & $1158203(96.64)$ \\
\hline
\end{tabular}

$1102757(39.43) \quad 472551(39.43)$

$\leq$ High School or GED/

Unknown

Associate/Some College Credit

$\geq$ Bachelor's

Missing

Pre-pregnancy Smoking Status (\%)

Nonsmoker

Smoker/Unknown/Not Stated

Missing

Pre-pregnancy BMI (\%)

Under Weight-Normal $\leq 24.9$

Overweight 25.0-29.9

Obesity $\geq 30.0 /$ Unknown/

Not Stated

Missing

Pre-pregnancy Diabetes Status (\%)

No/Unknown/Not Stated

2675048 (95.66)

Yes

$21149(0.76)$

$1146820(95.69)$

Missing

$100214(3.58)$

$9004(0.75)$

$42637(3.56)$

Pre-pregnancy Hypertension Status (\%)

No/Unknown/Not Stated

2653410 (94.89)
Table 2 Univariate difference between training sample and validation sample (Continued)

models with either 14 or 10 predictors based on the training cohort (Fig. 1). The C-index was 0.645 after fitting the 10-predictor model on the validation data, indicating an acceptable model fit. Figure 2 showed the calibration plot based on the validation cohort to compare the average predicted probabilities and the average observed probabilities across quartiles. The average and range of both predicted and observed probability for each of the four potential subgroups were shown in Table 4, along with summarized maternal characteristics for each subgroup from the validation cohort.

For the first subgroup (i.e., first quartile), the average predicted and observed probabilities were $1.92 \%$ and $1.83 \%$ respectively, with a range of $0.55 \%$ for the predicted probability. A typical mother from this potential subgroup was between 30-34 years old, with a designation as white, married, with a bachelor's degree or higher education level, non-smoking, underweight to normal weight (BMI $\leq 24.9)$ before pregnancy, without notable pre-pregnancy risk factors (i.e., diabetes, hypertension, previous preterm birth), and without infertility treatment. The second subgroup (i.e., second quartile) had an average predicted and an average observed probability of $2.46 \%$ and $2.33 \%$ respectively, with a range of 
Table 3 The estimate and adjusted OR of logistic regression analysis on the training cohort

\begin{tabular}{|c|c|c|c|}
\hline Parameter & Estimate & Adjusted OR (95\% Cl) & $P$ value \\
\hline Intercept & -3.7154 & - & $<.0001$ \\
\hline \multicolumn{4}{|l|}{ Mothers' Age (\%) } \\
\hline$\leq 24$ Years & - & $1.0(1.0-1.0)$ & - \\
\hline 25-29 Years & 0.0129 & $1.013(0.995,1.032)$ & 0.169 \\
\hline 30-34 Years & 0.1221 & $1.130(1.108,1.152)$ & $<.0001$ \\
\hline$\geq 35$ Years & 0.3034 & $1.354(1.325,1.385)$ & $<.0001$ \\
\hline \multicolumn{4}{|l|}{ Mothers' Nativity (\%) } \\
\hline Born in U.S. & - & $1.0(1.0-1.0)$ & - \\
\hline Born Outside U.S. /Unknown/Not Stated & -0.1274 & $0.880(0.863,0.898)$ & $<.0001$ \\
\hline \multicolumn{4}{|l|}{ Mothers' Race (\%) } \\
\hline White & - & $1.0(1.0-1.0)$ & - \\
\hline Black & 0.5727 & $1.773(1.743,1.803)$ & $<.0001$ \\
\hline American Indian/Alaskan Native/Asian or Pacific Islander & 0.0917 & $1.096(1.066,1.127)$ & $<.0001$ \\
\hline \multicolumn{4}{|l|}{ Mothers' Hispanic Origin (\%) } \\
\hline Non-Hispanic/Hispanic Origin Not Stated & - & $1.0(1.0-1.0)$ & - \\
\hline Hispanic & 0.0323 & $1.033(1.013,1.053)$ & 0.009 \\
\hline \multicolumn{4}{|l|}{ Marital Status (\%) } \\
\hline Married & - & $1.0(1.0-1.0)$ & - \\
\hline Unmarried & 0.2819 & $1.326(1.304,1.347)$ & $<.0001$ \\
\hline \multicolumn{4}{|l|}{ Mothers' Education (\%) } \\
\hline$\leq$ High School or GED/Unknown & - & $1.0(1.0-1.0)$ & - \\
\hline Associate/Some College Credit & -0.1725 & $0.842(0.828,0.856)$ & $<.0001$ \\
\hline$\geq$ Bachelor's & -0.3382 & $0.713(0.698,0.729)$ & $<.0001$ \\
\hline Missing & 0.0031 & $1.003(0.966,1.042)$ & 0.8727 \\
\hline \multicolumn{4}{|l|}{ Pre-pregnancy Smoking Status (\%) ${ }^{a}$} \\
\hline Nonsmoker & - & $1.0(1.0-1.0)$ & - \\
\hline Smoker/Unknown/Not Stated & 0.1677 & $1.183(1.160,1.206)$ & $<.0001$ \\
\hline \multicolumn{4}{|l|}{ Pre-pregnancy BMI (\%) ${ }^{\mathrm{a}}$} \\
\hline Under Weight-Normal $\leq 24.9$ & - & $1.0(1.0-1.0)$ & - \\
\hline Overweight 25.0-29.9 & -0.0174 & $0.983(0.966,1.000)$ & 0.0472 \\
\hline Obesity $\geq 30.0 /$ Unknown/Not Stated & 0.1195 & $1.127(1.109,1.145)$ & $<.0001$ \\
\hline \multicolumn{4}{|l|}{ Pre-pregnancy Diabetes Status (\%) ${ }^{a}$} \\
\hline No/Unknown/Not Stated & - & $1.0(1.0-1.0)$ & - \\
\hline Yes & 0.5741 & $1.776(1.685,1.871)$ & $<.0001$ \\
\hline \multicolumn{4}{|l|}{ Pre-pregnancy Hypertension Status (\%) ${ }^{a}$} \\
\hline No/Unknown/Not Stated & - & $1.0(1.0-1.0)$ & \\
\hline Yes & 0.6849 & $1.984(1.913,2.056)$ & $<.0001$ \\
\hline \multicolumn{4}{|l|}{ Previous Preterm Birth Status (\%) ${ }^{a}$} \\
\hline No/Unknown/Not Stated & - & $1.0(1.0-1.0)$ & - \\
\hline Yes & 1.0999 & $3.004(2.929,3.081)$ & $<.0001$ \\
\hline \multicolumn{4}{|l|}{ Infertility Treatment Usage Status (\%) ${ }^{a}$} \\
\hline No/Unknown/Not Stated & - & $1.0(1.0-1.0)$ & - \\
\hline Yes & 1.6299 & $5.103(4.888,5.328)$ & $<.0001$ \\
\hline
\end{tabular}


Table 3 The estimate and adjusted OR of logistic regression analysis on the training cohort (Continued)

\begin{tabular}{llll}
\hline No/Not Applicable/Unknown/Not Stated & - & $1.0(1.0-1.0)$ & - \\
Yes & -0.1988 & $0.820(0.769,0.873)$ & \\
Delivery Payment Source (\%) ${ }^{a}$ & & & \\
Medicaid & - & $1.0(1.0-1.0)$ & $<.0001$ \\
Private Insurance & -0.0352 & $0.965(0.948,0.983)$ & - \\
Self-pay/Other/Unknown & 0.0762 & $1.079(1.054,1.105)$ & $<.0001$ \\
\hline
\end{tabular}

${ }^{a}$ : For the following parameters after mothers' education, missing observations were automatically excluded from the analysis, and the corresponding parameters were automatically set to 0 due to they are from the same subset

$0.52 \%$ for the predicted probability. Mothers from the second potential subgroup shared very similar characteristics with a typical mother from the first subgroup, with the exception of age (slightly younger, 25-29 years old) and slightly lower education level (associate degree or some college credit). The average and range of predicted probability for the third subgroup (i.e., third quartile) were $3.22 \%$ and $0.95 \%$; and the observed probability was $3.24 \%$. Similar to trends observed from the second subgroup (in comparison with the first subgroup), a typical mother from the third subgroup was younger $(\leq 24$ years old) and with less education ( $\leq$ high school or GED/unknown). Lastly, the average predicted and observed probabilities for the highest risk subgroup (i.e., last 25\% of data) were $6.02 \%$ and $6.07 \%$ respectively, with the predicted probability range of $60.6 \%$. Mothers in this high- risk subgroup exhibit much different characteristics from the other three subgroups. They tended to be younger $(\leq 24$ years old), Black, unmarried, with a high school/GED or less education level, and generally obese ( $\geq 30.0 \mathrm{BMI}$ ). Moreover, compared to the other three subgroups, a relatively higher percentage of mothers in this high-risk subgroup had pre-pregnancy diabetes, hypertension, previous preterm birth, and infertility treatment usage.

\section{CART model}

For the CART model, sub-categories were collapsed for a couple of risk factors. The missing subgroup of previous preterm birth status was combined with the "no" group; and the race category of American Indian/Alaskan Native/ Asian or Pacific Islander was combined with the White

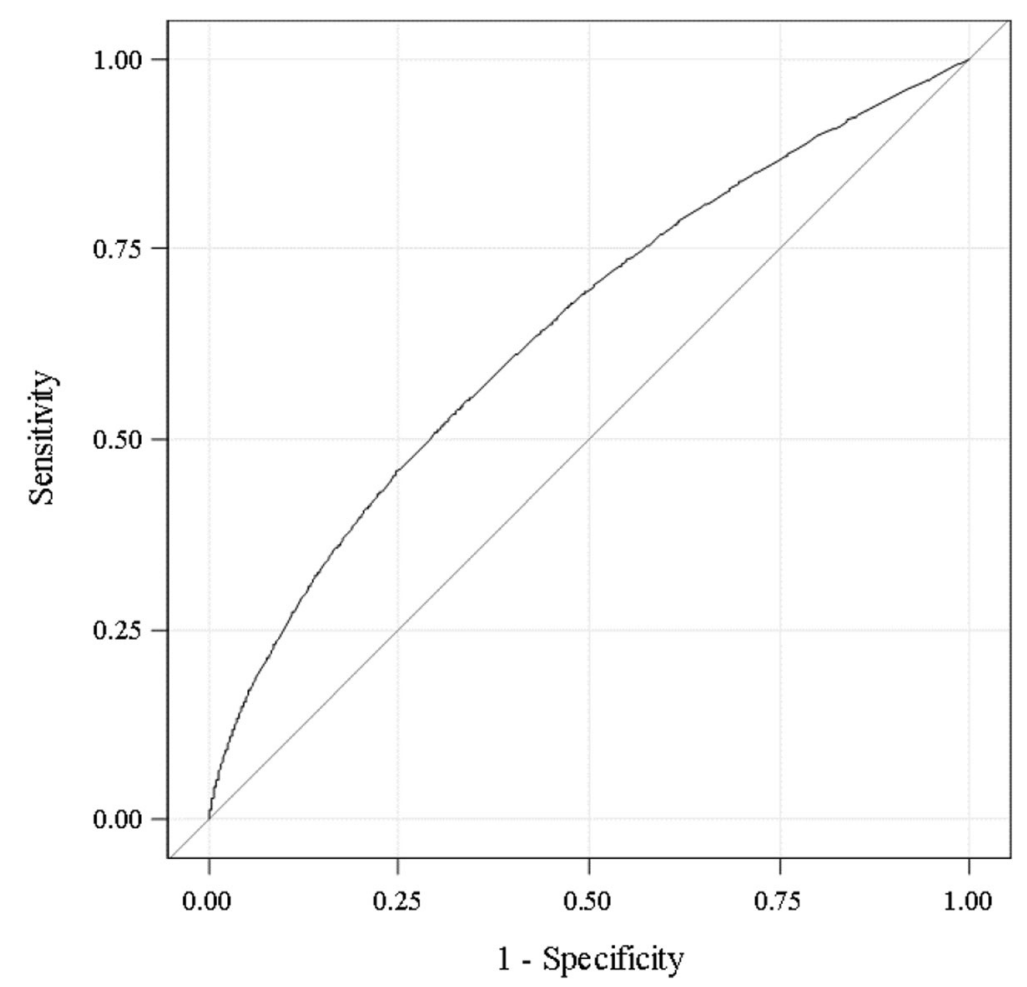

Fig. 1 ROC curve from logistic regression on the training dataset (Area under the curve $=0.646$ ) 


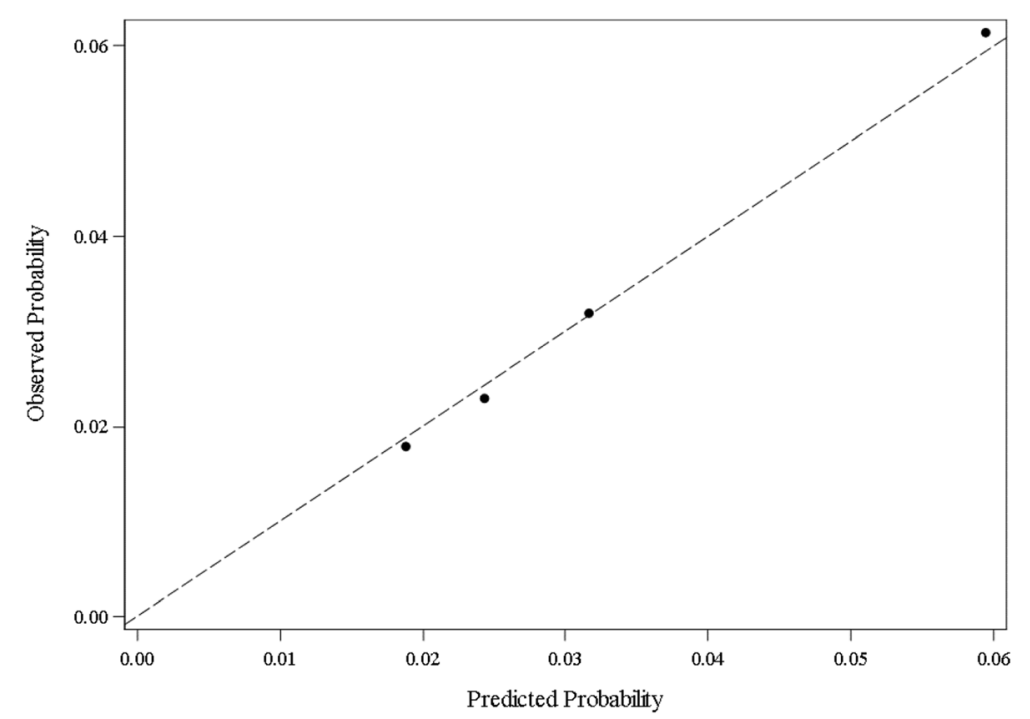

Fig. 2 Calibration plot from the validation sample. Observed vs. Predicted Probability across the quartiles

group. Based on a pre-specified stopping rule of having the terminal node size no less than $0.5 \%$ of the total sample and the binary Gini splitting rule, the CART tree was created to explore the unknown interactions among the risk factors and identify potential risk subgroups (Fig. 3). Overall, the CART model from the training cohort produced a misclassification rate of 0.034 and a $\mathrm{C}$-index of 0.579 . Moreover, the misclassification rate was 0.034 and the c-index was 0.578 from the validation cohort. By the percentage representing the observed prevalence of ePTB, CART identified four subgroups. Previous preterm birth status was identified as the most discriminating predictor for ePTB, followed by mothers' race.

From training cohort, $14.41 \%$ of mothers with a preterm birth history and a race designation as Black had an ePTB experience $(n=16,750)$, indicating a higher risk of ePTB for Black mothers with a preterm birth history. The correspondent percentage of this subgroup from the validation cohort is $15.02 \%(n=7,085)$. This subgroup totally accounted for $0.60 \%$ of the overall 2014 U.S. births. $8.96 \%$ and $8.70 \%$ of mothers with a preterm birth history and a race designation as White had an ePTB experience from training $(n=57,951)$ and validation ( $n=24,888$ ), and the subgroup birth prevalence (SBP) was $2.07 \%$. Women without a preterm birth history who were Black had an ePTB experience of $5.37 \%(n=431,222)$; while $2.75 \%$ of mothers without a preterm birth history who were White had an ePTB experience $(n=2,290,488)$. The correspondent rates for the identical subgroups from the validation cohort are $5.35 \%(n=185,418)$ and $2.76 \%(n=981,070)$. These two subgroups accounted for $15.44 \%$ and $81.89 \%$ of the overall birth data, respectively.
It is also informative to interpret the CART tree in terms of risk factors that increase or decrease the probability of ePTB. One can compare the rates of ePTB among the four potential subgroups to the average rate of ePTB of the total sample $(3.35 \%$, 3.36\% for training and validation cohort, respectively). Three subgroups (with preterm birth history and Black, with preterm birth history and White, without preterm birth history and Black) had an increased probability of ePTB compared to the subgroup without a preterm birth history who were White.

\section{Discussion}

This large sampled pioneer study aimed to explore potential risk factors and their interactions, and identify subgroup for the ePTB population via both logistic regression model and the CART model. Several important findings emerged from the current study. First, a subset of the most important and relevant covariates have been identified among the 14 risk factors examined, such as race, diabetes history, hypertension history, preterm birth history, and infertility treatment usage. Second, although logistic regression model identified a set of 10 predictors for the prevalence of ePTB, the CART model was able to examine multiple and complicated interactions among the selected predictors. The CART model clearly identified that the subgroup with a preterm birth history and a race designation as Black had the highest risk for ePTB. Third, although not presented in the current work, the risk ratios (RR) of a particular subgroup from the CART terminal nodes can be calculated to compare with the RR of other subgroups via the observed probabilities. RR also indirectly can inform the risk factors for ePTB. 
Table 4 The ePTB subgroup predicted /observed probability and maternal characteristics in validation cohort via logistic regression

\begin{tabular}{|c|c|c|c|c|}
\hline \multirow[t]{3}{*}{ Variable } & \multicolumn{4}{|l|}{ Subgroup } \\
\hline & 1st Quartile & 2nd Quartile & 3rd Quartile & 4th Quartile \\
\hline & $N=299529$ & $N=299078$ & $N=299993$ & $N=299861$ \\
\hline \multicolumn{5}{|l|}{ Probability (\%) } \\
\hline Average Predicted & 1.92 & 2.46 & 3.22 & 6.02 \\
\hline Range Predicted & 0.55 & 0.52 & 0.95 & 60.6 \\
\hline Average Observed & 1.83 & 2.33 & 3.24 & 6.07 \\
\hline \multicolumn{5}{|l|}{ Mothers' Age (\%) } \\
\hline$\leq 24$ Years & $36603(12.22)$ & 70681 (23.63) & 127739 (42.58) & 105995 (35.35) \\
\hline 25-29 Years & $120779(40.32)$ & $83600(27.95)$ & $68003(22.67)$ & 71979 (24.00) \\
\hline 30-34 Years & $129538(43.25)$ & 78439 (26.23) & $56362(18.79)$ & 60927 (20.32) \\
\hline$\geq 35$ Years & $12609(4.21)$ & 66358 (22.19) & 47889 (15.96) & 60960 (20.33) \\
\hline \multicolumn{5}{|l|}{ Mothers' Race (\%) } \\
\hline White & $259978(86.80)$ & 273311 (91.38) & $260128(86.71)$ & 114119 (38.06) \\
\hline Black & $0(0.00)$ & $872(0.29)$ & $18661(6.22)$ & $172970(57.68)$ \\
\hline American Indian/Alaskan Native/Asian or Pacific Islander & $39551(13.20)$ & $24895(8.32)$ & $21204(7.07)$ & $12772(4.26)$ \\
\hline \multicolumn{5}{|l|}{ Marital Status (\%) } \\
\hline Married & 296804 (99.09) & $246717(82.49)$ & $92320(30.77)$ & $80790(26.94)$ \\
\hline Unmarried & $2725(0.91)$ & $52361(17.51)$ & $207673(69.23)$ & $219071(73.06)$ \\
\hline \multicolumn{5}{|l|}{ Mothers' Education (\%) } \\
\hline$\leq$ High School or GED/Unknown & $10988(3.67)$ & $93778(31.36)$ & $192086(64.03)$ & 175699 (58.59) \\
\hline Associate/Some College Credit & $69843(23.32)$ & $117843(39.40)$ & $69455(23.15)$ & $79732(26.59)$ \\
\hline$\geq$ Bachelor's & $217614(72.65)$ & $71541(23.92)$ & $21886(7.30)$ & 35359 (11.79) \\
\hline Missing & $1084(0.36)$ & $15916(5.32)$ & $16566(5.52)$ & $9071(3.03)$ \\
\hline \multicolumn{5}{|l|}{ Pre-pregnancy Smoking Status (\%) } \\
\hline Nonsmoker & $295313(98.59)$ & $262159(87.66)$ & $234907(78.30)$ & $217556(72.55)$ \\
\hline Smoker/Unknown/Not Stated & $3132(1.05)$ & $21003(7.02)$ & $48520(16.17)$ & $73234(24.42)$ \\
\hline Missing & $1084(0.36)$ & $15916(5.32)$ & $16566(5.52)$ & $9071(3.03)$ \\
\hline \multicolumn{5}{|l|}{ Pre-pregnancy BMI (\%) } \\
\hline Under Weight-Normal $\leq 24.9$ & $183032(61.11)$ & $142007(47.48)$ & 119757 (39.92) & $108130(36.06)$ \\
\hline Overweight 25.0-29.9 & $82956(27.70)$ & $67818(22.68)$ & $70451(23.48)$ & $62770(20.93)$ \\
\hline Obesity $\geq 30.0 /$ Unknown/Not Stated & $32457(10.84)$ & $73337(24.52)$ & $93219(31.07)$ & $119890(39.98)$ \\
\hline Missing & $1084(0.36)$ & $15916(5.32)$ & $16566(5.52)$ & $9071(3.03)$ \\
\hline \multicolumn{5}{|l|}{ Pre-pregnancy Diabetes Status (\%) } \\
\hline No/Unknown/Not Stated & $298445(99.64)$ & $283149(94.67)$ & $282480(94.16)$ & $282746(94.29)$ \\
\hline Yes & $0(0.00)$ & $13(0.00)$ & $947(0.32)$ & $8044(2.68)$ \\
\hline Missing & $1084(0.36)$ & $15916(5.32)$ & $16566(5.52)$ & $9071(3.03)$ \\
\hline \multicolumn{5}{|l|}{ Pre-pregnancy Hypertension Status (\%) } \\
\hline No/Unknown/Not Stated & 298445 (99.64) & $283162(94.68)$ & $282293(94.10)$ & $273911(91.35)$ \\
\hline Yes & $0(0.00)$ & $0(0.00)$ & $1134(0.38)$ & $16879(5.63)$ \\
\hline Missing & $1084(0.36)$ & $15916(5.32)$ & $16566(5.52)$ & $9071(3.03)$ \\
\hline \multicolumn{5}{|l|}{ Previous Preterm Birth Status (\%) } \\
\hline No/Unknown/Not Stated & 298445 (99.64) & $283162(94.68)$ & $283427(94.48)$ & $258817(86.31)$ \\
\hline Yes & $0(0.00)$ & $0(0.00)$ & $0(0.00)$ & $31973(10.66)$ \\
\hline Missing & $1084(0.36)$ & $15916(5.32)$ & $16566(5.52)$ & $9071(3.03)$ \\
\hline
\end{tabular}


Table 4 The ePTB subgroup predicted /observed probability and maternal characteristics in validation cohort via logistic regression (Continued)

Infertility Treatment Usage Status (\%)

No/Unknown/Not Stated

$298445(99.64)$

$283162(94.68)$

$283427(94.48)$

$272918(91.01)$

Yes

$0(0.00)$

Missing

$1084(0.36)$

$0(0.00)$

$0(0.00)$

$17872(5.96)$

Previous preterm birth status and race were the most discriminating predictors for ePTB by the CART model, while another eight predictors were identified by the logistic regression analyses. As a well-known traditional statistical approach, logistic regression provided predicted probabilities based on the important demographics and characteristics for ePTB; however, it cannot identify complicated interactions among risk factors. On the other hand, the CART model presents a more straightforward picture of the potential high risk subgroups for ePTB for whom targeted prevention efforts can be implemented. Moreover, each subgroup accounted for a different percent of the overall simple size. Thus the difference in ePTB prevalence among the four subgroups identified by the CART model was much larger than that identified by the logistic regression model. Coupling both statistical approaches provides more efficiency for analyzing the overall objective of this study. It also further exemplifies the statistical analysis for similar studies.

Additionally, from a long-term perspective, this pioneering study provides valuable information and direction for our further targeted subgroup enrichment clinical trials aiming at decreasing the prevalence of
ePTB among the interactive risk subgroups via supplement pregnant women with DHA.

There are some limitations with this study. Some risk factors contained missing values and/or values of "Not Applicable", "Unknown," and "Not Stated," which added complexity to the proposed analyses. However, data management is unavoidable for any concrete project, and we face the same issue for such a large database regarding birth data for the whole country. The solution taken was from an objective and general perspective, which could deduce the reasonable and acceptable results. Additionally, the risk predictors explored in this paper mainly from mothers' demographics factors and Maternal pre-pregnancy characteristics, and it does include more highly specific biomarkers. This is due to no such predictors collected in the analysis database. Potentially, this limitation may lead to the relatively low c-index for both models. Further application and reference for these two models should be precautioned.

\section{Conclusions}

This study revealed 14 maternal characteristic variables that can be used reliably to identify risk factor subgroups

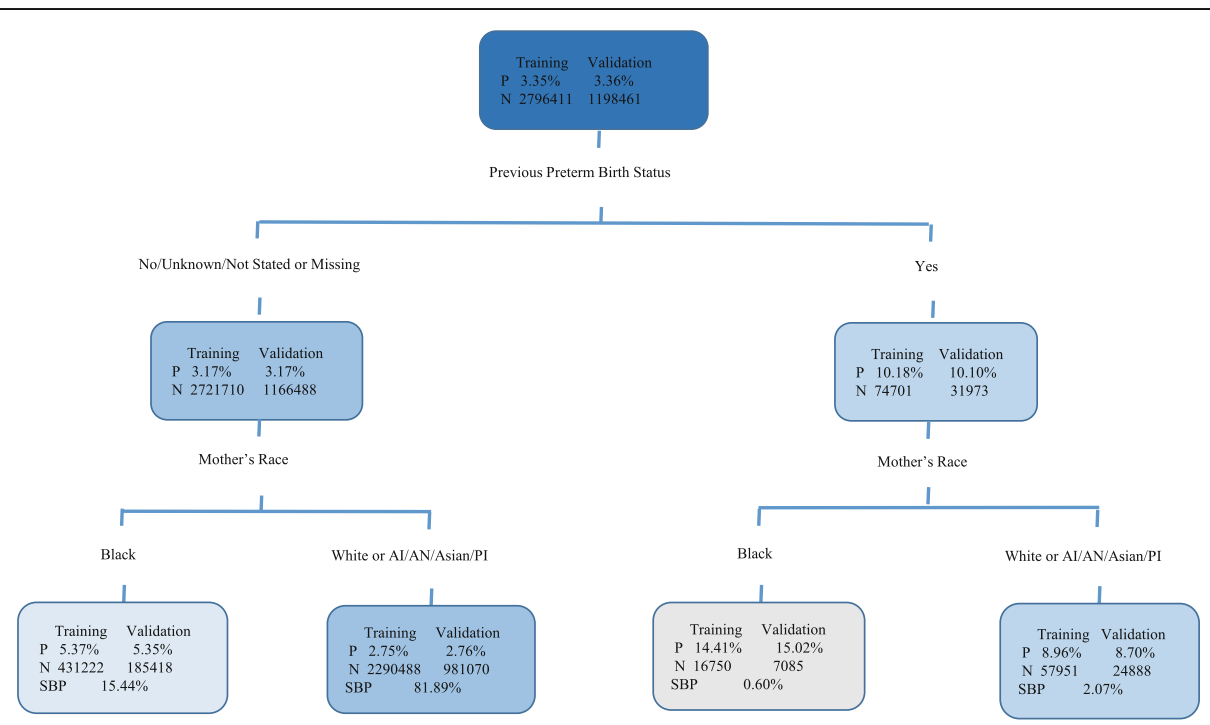

Fig. 3 Classification and Regression Tree model for predicting ePTB. Legend: The probability of ePTB (P) and the number of subject (N) are all given inside of each node for both training and validation cohort. In each end node, the subgroup birth prevalence (SBP) is also calculated. Al = American Indian; AN = Alaskan Native; PI = Pacific Islander 
for ePTB either through a logistic regression model and/ or a CART model. Moreover, both models may be used efficiently to identify high risk subgroups for further enrichment clinical trial design.

\section{Abbreviations}

BMI: Body mass index; CART: Classification and regression tree; CDC: Centers for Disease Control and Prevention's; Cl: Confidence intervals; DC: District of Columbia; DHA: Docosahexaenoic acid; ePTB: Early preterm birth; GED: General educational development; NCHS: National Center for Health Statistics; OR: Odds ratios; RR: Risk ratios; SBP: Subgroup birth prevalence

\section{Acknowledgements}

Anyone who contributed to this paper is in the author list, and all of them meet the criteria for authorship.

\section{Funding}

This study was supported in part by a National Institutes of Health $(\mathrm{NIH})$ Clinical and Translational Science Award Grant (UL1 TR000001, formerly UL1RR033179), awarded to the University of Kansas Medical Center.

\section{Availability of data and materials}

The dataset supporting the conclusions of this article is available in the Centers for Disease Control and Prevention repository: http://www.cdc.gov/ nchs/data_access/Vitalstatsonline.htm.

\section{Authors' contributions}

$L G$ and $C Z$ completed the data analysis under the BG's guidance. $C Z$ also carried out the literature review and drafted the manuscript. LG also provided the comprehensive work polish work. JK provided guidance of CART model SAS execution. SC gave professional information early preterm birth. All authors contributed reviewed and approved the final manuscript.

\section{Competing interests}

The authors declare that they have no competing interests. Moreover, this manuscript reflects the views of the authors and should not be construed to represent the FDA's views or policies. Lili Garrard completed this work as a PhD student in the Department of Biostatistics at the University of Kansas Medical Center. The content is solely the responsibility of the authors and does not necessarily represent the official views of the National Institutes of Health.

\section{Consent for publication}

Not applicable.

\section{Ethics approval and consent to participate}

Not applicable.

\section{Author details}

'Department of Biostatistics, University of Kansas Medical Center, Mail Stop 1026, 3901 Rainbow Blvd., Kansas City, KS 66160, USA. ²Division of Biometrics III, OB/OTS/CDER, U.S. Food and Drug Administration, Silver Spring, MD 20993, USA. ${ }^{3}$ Department of Dietetics and Nutrition, School of Health Professions, University of Kansas Medical Center, Mail Stop 1026, 3901 Rainbow Blvd., Kansas City, KS 66160, USA.

Received: 14 September 2016 Accepted: 8 December 2016 Published online: 10 January 2017

\section{References}

1. Hamilton BE, Martin JA, Osterman M, Curtin S, Matthews T. Births: Final Data for 2014. Natl Vital Stat Rep. 2015;64(12):1-64.

2. Catov JM, Bertolet M, Chen YF, Evans RW, Hubel CA. Nonesterified fatty acids and spontaneous preterm birth: a factor analysis for identification of risk patterns. Am J Epidemiol. 2014;179(10):1208-15.

3. Blencowe H, Cousens S, Oestergaard MZ, Chou D, Moller AB, Narwal R, Adler A, Vera Garcia C, Rohde S, Say L, et al. National, regional, and worldwide estimates of preterm birth rates in the year 2010 with time trends since 1990 for selected countries: a systematic analysis and implications. Lancet. 2012;379(9832):2162-72.
4. Witt WP, Cheng ER, Wisk LE, Litzelman K, Chatterjee D, Mandell K, Wakeel F. Preterm birth in the United States: the impact of stressful life events prior to conception and maternal age. Am J Public Health. 2014;104 Suppl 1:S73-80.

5. Norman M. Preterm birth-an emerging risk factor for adult hypertension? Semin Perinatol. 2010;34(3):183-7.

6. Keijzer-Veen MG, Dulger A, Dekker FW, Nauta J, van der Heijden BJ. Very preterm birth is a risk factor for increased systolic blood pressure at a young adult age. Pediatr Nephrol. 2010;25(3):509-16.

7. Gravett MG, Rubens CE. A framework for strategic investments in research to reduce the global burden of preterm birth. Am J Obstet Gynecol. 2012 207(5):368-73

8. McCormick MC. The contribution of low birth weight to infant mortality and childhood morbidity. N Engl J Med. 1985;312(2):82-90.

9. Russell RB, Green NS, Steiner CA, Meikle S, Howse JL, Poschman K, Dias T, Potetz L, Davidoff MJ, Damus K. Cost of hospitalization for preterm and low birth weight infants in the United States. Pediatrics. 2007;120(1):e1-9.

10. Treyvaud K, Doyle LW, Lee KJ, Roberts G, Cheong JL, Inder TE, Anderson PJ. Family functioning, burden and parenting stress $2 y e a r s$ after very preterm birth. Early Hum Dev. 2011;87(6):427-31.

11. Lawn JE, Gravett MG, Nunes TM, Rubens CE, Stanton C. Global report on preterm birth and stillbirth (1 of 7): definitions, description of the burden and opportunities to improve data. Bmc Pregnancy Childb. 2010;10(1):1.

12. Christopherson M, Penrose C. 1240 An Evaluation of the Burden of Premature Birth on a United Kingdom Regional Paediatric Intensive Care Service. Pediatr Res. 2010;68:614-5.

13. Martius JA, Steck T, Oehler MK, Wulf K-H. Risk factors associated with preterm $(<37+0$ weeks) and early preterm birth $(<32+0$ weeks): univariate and multivariate analysis of 106345 singleton births from the 1994 statewide perinatal survey of Bavaria. Eur J Obstet Gynecol Reprod Biol. 1998;80(2):183-9.

14. Creasy RK. Preterm birth prevention: where are we? Am J Obstet Gynecol. 1993;168(4):1223-30.

15. Saccone $G$, Perriera $L$, Berghella $V$. Prior uterine evacuation of pregnancy as independent risk factor for preterm birth: a systematic review and metaanalysis. Am J Obstet Gynecol. 2016;214(5):572-91.

16. Gandhimadhi D, Mythili R. Periodontal infection as a risk factor for preterm low birth weight. J Indian Soc Periodontol. 2010;14(2):114-20.

17. Little SE, Janiak E, Bartz D, Smith NA. Second trimester dilation and evacuation: a risk factor for preterm birth? J Perinatol. 2015;35(12):1006-10.

18. Connealy BD, Carreno CA, Kase BA, Hart LA, Blackwell SC, Sibai BM. A history of prior preeclampsia as a risk factor for preterm birth. Am J Perinatol. 2014;31(6):483-8.

19. Hiltunen LM, Laivuori H, Rautanen A, Kaaja R, Kere J, Krusius T, Rasi V, Paunio M. Factor V Leiden as a risk factor for preterm birth-a population-based nested case-control study. J Thromb Haemost. 2011:9(1):71-8.

20. Simhan HN, Bodnar LM, Kim KH. Lower genital tract inflammatory milieu and the risk of subsequent preterm birth: an exploratory factor analysis. Paediatr Perinat Epidemiol. 2011;25(3):277-82.

21. Stephansson $\mathrm{O}$, Larsson $\mathrm{H}$, Pedersen L, Kieler $\mathrm{H}$, Granath F, Ludvigsson JF, Falconer H, Ekbom A, Sorensen HT, Norgaard M. Crohn's disease is a risk factor for preterm birth. Clin Gastroenterol Hepatol. 2010;8(6):509-15.

22. Saigal S, Doyle LW. An overview of mortality and sequelae of preterm birth from infancy to adulthood. Lancet. 2008;371 (9608):261-9.

23. Carlson SE, Colombo J, Gajewski BJ, Gustafson KM, Mundy D, Yeast J, Georgieff MK, Markley LA, Kerling EH, Shaddy DJ. DHA supplementation and pregnancy outcomes. Am J Clin Nutr. 2013;97(4):808-15.

24. Neerhof MG, Cravello C, Haney El, Silver RK. Timing of labor induction after premature rupture of membranes between 32 and 36 weeks' gestation. Am J Obstet Gynecol. 1999;180(2):349-52.

25. Tan HZ, Wen SW, Chen XK, Demissie K, Walker M. Early prediction of preterm birth for singleton, twin, and triplet pregnancies. Eur J Obstet Gyn R B. 2007; 131(2):132-7.

26. CDC. User Guide to the 2014 NatalityPublic Use File. 2014.

27. Loh WY. Classification and regression trees. Wiley Interdisciplinary Reviews: Data Mining and Knowledge Discovery. 2011;1(1):14-23.

28. Lei Y, Nollen N, Ahluwahlia JS, Yu Q, Mayo MS. An application in identifying high-risk populations in alternative tobacco product use utilizing logistic regression and CART: a heuristic comparison. BMC Public Health. 2015;15(1):1-9.

29. Nollen NL, Ahluwalia JS, Lei Y, Yu Q, Scheuermann TS, Mayo MS. Adult Cigarette Smokers at Highest Risk for Concurrent Alternative Tobacco Product Use Among a Racially/Ethnically and Socioeconomically Diverse Sample. 2015. 
30. Lemon SC, Roy J, Clark MA, Friedmann PD, Rakowski W. Classification and regression tree analysis in public health: methodological review and comparison with logistic regression. Ann Behav Med. 2003;26(3):172-81.

31. Breiman L, Friedman J, Olshen R, Stone C. Classification and regression trees. Monterey: Wadsworth; 1984.

32. Gordon L. Using Classification and Regression Trees (CART) in SAS ${ }^{\bullet}$ Enterprise Miner TM For Applications in Public Health. Public Health. 2013;2013. http:// support.sas.com/resources/papers/proceedings13/089-2013.pdf.

Submit your next manuscript to BioMed Central and we will help you at every step:

- We accept pre-submission inquiries

- Our selector tool helps you to find the most relevant journal

- We provide round the clock customer support

- Convenient online submission

- Thorough peer review

- Inclusion in PubMed and all major indexing services

- Maximum visibility for your research

Submit your manuscript at www.biomedcentral.com/submit
Biomed Central 